Chirurgia (2020) 115: 289-306

No. 3, May - June

Copyright@ Celsius

http://dx.doi.org/10.21614/chirurgia.115.3.289

\title{
SRED-ARCE Recommendations for Minimally Invasive Interventions During the COVID-19 Pandemic in Romania
}

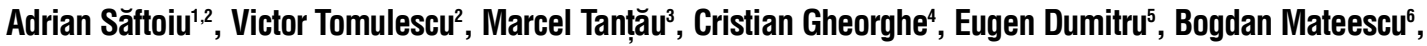 \\ Lucian Negreanu', Mariana Jinga ${ }^{8}$, Andrada Seicean ${ }^{3}$, Mihai Ciocîrlan ${ }^{9}$, Vasile Drug ${ }^{10}$, Mircea Mănuc ${ }^{11}$, Răzvan Popescu ${ }^{12}$, \\ Călin Tiu ${ }^{13}$, Vasile Bințințan ${ }^{14}$, Valentin Calu ${ }^{15}$, Valeriu Șurlini ${ }^{16}$, Florin Turcu ${ }^{2}$, Florin Zaharie ${ }^{17}$, Dan Ulmeanu ${ }^{18}$, Dan Brebu ${ }^{19}$, \\ Alexandru Nicolau ${ }^{20}$, Mircea Lițescu ${ }^{21}$, Bogdan Diaconescu ${ }^{20}$, Ciprian Duță̌ ${ }^{19}$, Cătălin Copăescu ${ }^{2 *}$
}

\author{
${ }^{1}$ Research Center of Gastroenterology and Hepatology Craiova, University of Medicine and Pharmacy Craiova, Romania \\ ${ }^{2}$ Ponderas Academic Hospital Bucharest, Romania \\ Grigore T. Popa, University of Medicine and Pharmacy, Iași, Romania \\ ${ }^{3}$ Regional Institute of Gastroenterology and Hepatology Cluj-Napoca, Iuliu Hațieganu University of Medicine and Pharmacy, \\ Cluj-Napoca, Romania \\ ${ }^{4}$ Center of Gastroenterology and Hepatology Fundeni, Carol Davila University of Medicine and Pharmacy, Bucharest, Romania \\ ${ }^{5}$ Faculty of Medicine, Ovidius University of Constanța, Romania \\ ${ }^{6}$ Gastroenterology Department, Colentina Clinical Hospital, Internal Medicine Department, Carol Davila University of Medicine and Pharmacy, \\ Bucharest, Romania \\ ${ }^{7}$ Gastroenterology Department, Emergency University Hospital, Carol Davila University of Medicine and Pharmacy, Bucharest, Romania \\ ${ }^{8}$ Carol Davila University of Medicine and Pharmacy, Dr. Carol Davila Central Military Emergency University Hospital, Bucharest, Romania \\ ${ }^{9} \mathrm{Carol}$ Davila University of Medicine and Pharmacy, Department of Gastroenterology, Emergency Clinical Hospital "Agrippa Ionescu", \\ Bucharest, Romania \\ ${ }^{10}$ Institute of Gastroenterology and Hepatology, Grigore T. Popa, University of Medicine and Pharmacy, lași, Romania \\ ${ }^{11}$ Center of Gastroenterology and Hepatology Fundeni, Carol Davila University of Medicine and Pharmacy, Bucharest, Romania \\ ${ }_{12}$ "Sf. Apostol Andrei” Emergency Hospital Constanta, " Ovidius” University of Medicine and Pharmacy Constanța, Romania \\ ${ }^{13}$ City Hospital Campina \\ ${ }^{14}$ First Surgical Clinic, University of Medicine and Pharmacy "Iuliu Hatieganu“, Cluj-Napoca, Romania \\ ${ }^{15}$ Department of Surgery, Elias University Emergency Hospital, Bucharest, Romania \\ ${ }^{16} 1^{\text {st }}$ Surgery Department, Emergency Hospital, University of Medicine and Pharmacy of Craiova, Romania \\ ${ }^{17}$ Third Surgical Clinic, University of Medicine and Pharmacy "Iuliu Hatieganu“, Cluj-Napoca, Romania \\ ${ }^{18}$ Baneasa Regina Maria Hospital; "Titu Maiorescu" University of Medicine and Pharmacy Bucharest, Romania \\ ${ }^{19}$ University of Medicine and Pharmacy "Victor Babes" Timișoara, Romania \\ ${ }^{20}$ Department of Surgery, "Floreasca" Emergency Hospital, Bucharest Romania \\ 21"Sfantul Ioan" Emergency Hospital," Carol Davila" University of Medicine and Pharmacy Bucharest Romania
}

*Corresponding author: Catalin Copaescu, MD PhD

Associated Professor of Surgery

Ponderas Academic Hospital

Nicolae Caramfil Street, no. 85 A

district 1, Bucharest, Romania

E-mail: catalin.copaescu@ponderas-ah.ro

\section{Rezumat}

Recomandările SRED-ARCE pentru intervențiile minim invazive în timpul pandemiei COVID-19 în România

Societatea Română de Endoscopie Digestivă (SRED) şi Asociația Română de Chirurgie Endoscopică (ARCE) au decis să înființeze un grup de lucru comun pentru a elabora recomandările necesare pentru organizarea procedurilor minim-invazive diagnostice şi intervenționale, în contextul pandemiei COVID-19. Recomandările 
se bazează pe ghidurile societăților internaționale de endoscopie şi gastroenterologie (ESGE / BSG / ASGE / ACG / AGA), respectiv chirurgie endoscopică (EAES \& SAGES) (4-8), pe experiența țărilor afectate grav de pandemie (Italia, Franța, Spania, SUA, Germania, etc.) şi vor fi aplicată în limitele măsurilor impuse la nivel local şi guvernamental de către autoritățile competente. Pe de altă parte, aceste recomandări trebuie să aibă o evoluție dinamică, în funcție de tendința ascendentă sau descendentă a pandemiei COVID-19 la nivel regional şi local, dar şi în funcție de concluziile societăților profesionale şi academice, necesitând analize periodice bazate pe publicarea de recomandări suplimentare sau studii clinice internaționale. Obiectivele recomandărilor SRED şi ARCE vizează organizarea de activități de endoscopie şi chirurgie laparoscopică, fiind aplicate nediscriminatoriu în scop diagnostic sau terapeutic, urmărind beneficiile demonstrate ale acestor proceduri, în condiții sigure pentru pacienți şi personalul medical.

Cuvint cheie: COVID-19

\begin{abstract}
The Romanian Society of Digestive Endoscopy (SRED) and the Romanian Association of Endoscopic Surgery (ARCE) have decided to establish a joint working group to elaborate specific recommendations for organizing the diagnostic and the minimally invasive interventional procedures, in the context of the COVID-19 pandemic. The recommendations are based on the guidelines of the international societies of endoscopy and gastroenterology (ESGE / BSG / ASGE / ACG / AGA), respectively endoscopic surgery (EAES \& SAGES) (4-8), on the experience of countries severely affected by the pandemic (Italy, France, Spain, USA, Germany, etc.) and they will be applied within the limits of measures imposed at local and governmental level by the competent authorities. On the other hand, these recommendations should have a dynamic evolution, depending on the upward or downward trend of the COVID-19 pandemic at regional and local level, but also according to the findings of professional and academic societies, requiring regular reviews based on the publication of further recommendations or international clinical trials. The objectives of the SRED and ARCE recommendations target the endoscopic and laparoscopic surgery activities, to support their nondiscriminatory used for diagnostic or therapeutic purposes, pursuing the demonstrated benefits of these procedures, in safe conditions for patients and medical staff.
\end{abstract}

Key word: COVID-19

\section{Introduction}

The COVID-19 pandemic associated with the widespread dissemination of incomplete and incorrect information on social media channels (1) has generated a public health crisis, which cannot be effectively managed by the health systems without the support of non-pharmaceutical interventions (quarantine measures, social distancing, suspending of the schools, high schools and universities' activities, etc.) (2). The exponential increase in the number of infected patients and the high proportion of deaths induced by the SARS-CoV-2 virus required the reorganization of medical systems, with a significant impact on the interventional endoscopy and endoscopic surgery units (3). The dramatic limitation of minimally invasive endoscopic and laparoscopic procedures has led to a massive decrease in the addressability of patients with gastroenterological and oncological diseases, with an impact difficult to assess on the evolution of various untreated pathologies. In addition, due to the unpredictable evolution 
of the pandemic, it is difficult to assess when and what will be the methods for whole resumption of medical services, in safe conditions for both the medical staff and patients.

The Romanian Society of Digestive Endoscopy (SRED) and the Romanian Association of Endoscopic Surgery (ARCE) have decided to establish a joint working group to elaborate specific recommendations for organizing the diagnostic and minimally invasive interventional procedures, in the context of the COVID-19 pandemic. The recommendations are based on the guidelines of the international societies of endoscopy and gastroenterology (ESGE / BSG / ASGE / ACG / AGA), as well as endoscopic surgery (EAES \& SAGES) (4-8), on the experience of countries severely affected by the pandemic (Italy, France, Spain, USA, Germany, etc.) and they will be applied within the limits of measures imposed at local and governmental level by the competent authorities. On the other hand, these recommendations must have a dynamic evolution, depending on the upward or downward trend of the COVID-19 pandemic at regional and local level, but also according to the findings of professional and academic societies, requiring regular reviews based on the publication of further recommendations or international clinical trials.

The objectives of the SRED and ARCE recommendations target the endoscopic and laparoscopic surgery activities, to support their non-discriminatory used for diagnostic or therapeutic purposes, pursuing the demonstrated benefits of these procedures, in safe conditions for patients and medical staff.

\section{COVID-19 Overview}

The first cases of pneumonia with acute respiratory distress syndrome (ARDS) were described in December 2019 in Wuhan, China, being caused by a new coronavirus, called SARS-CoV-2. The virus is highly contagious and the pan-demic declared by the WHO has spread exponentially in just 5 months to over 6 million cases, with over 370,000 deaths worldwide. On the other hand, the North-
South and East-West gradient of the epidemic severity at European level requires measures of varying intensity rather than universally valid guidelines or recommendations (9). The clinical presentation of COVID-19 includes, in addition to respiratory symptoms, digestive symptoms (nausea and vomiting, diarrhea, diffuse abdominal pain, loss of appetite, weight loss) in a variable proportion of patients, up to $20 \%$ in some studies (10-12), being possibly associated with a more severe course of the disease.

SARS-CoV-2 virus can be transmitted by direct exposure (respiratory droplets) or by contact with contaminated surfaces, conjunctival or mucosal contact, but also by faecal-oral transmission (13). The ACE-2 receptors, to which the virus binds, are found in the digestive tract, and viral RNA has been identified in the digestive mucosa or in the faeces (14) and even in the peritoneal fluid (15). Endoscopic and laparoscopic procedures are included in the category of aerosol generating procedures (16), being considered procedures with an increased risk of medical staff contamination (up to 10$20 \%$ in some European countries), who can transmit the infection themselves, generating epidemic micro-outbreaks at hospital or community level.

Infection control and prevention measures are extremely important, starting with defining separate circuits (COVID-19 positive and non-COVID-19), correct triage and patient risk stratification, pre-procedure patient testing with isolation of positive patients, as well as the correct usage of protective equipment and proper disinfection/sterilization of the employed equipment (8). Each institution where endoscopic and/or laparoscopic minimally invasive diagnostic or therapeutic interventions are performed must have dedicated procedures and operational protocols and properly trained staff to rigorously follow each step. Under these conditions, the risk of transmitting SARS-CoV-2 infection can be minimized, in both directions, from patients to medical staff, respectively from medical staff to patients (17). 


\section{Medical Staff Training}

The medical staff will maintain a reasonable distance from each patient during the steps preceding the endoscopic procedure (monitoring of vital parameters, presenting the instructions regarding the procedure and informed consent, biological samples collection, etc.).

It is mandatory to wash hands with soap and water and / or disinfectant before and after each interaction with the patient or after the contact with a potential source of infection, when wearing or removing the protective equipment (including gloves). Hand hygiene is achieved through the method of hands washing in 6 steps, for at least 20 seconds, after removing jewelry and watch, by using alcohol solutions.

Personal protective equipment (PPE) is required to avoid exposure to work-related accidents or illnesses. EPP consists of surgical masks or facial masks with respiratory filter FFP2/FFP3 (the version with or without valve), eye protection (goggles and visor), disposable gloves, long sleeved fluid repellent gown, head cove (caps), waterproof leg cover.

NB The mask is one of the most important parts of the protective equipment. The surgical mask creates a physical barrier between the carrier and the potential contaminated, being effective in blocking large particles, but not small droplets transmitted by sneezing, coughing or certain procedures that generate aerosols. Instead, respirators with FFP2 / FFP3 / N95 filter are effective protection devices in filtering small particles (up to 0.3 microns) that could be inhaled, being tightly mounted on the face. Respirators (approved by ANMDM) are currently recommended for aerosol generating procedures, including endoscopic and laparoscopic procedures, regardless the risk of patients to be infected with the SARS-VOC-2 virus (12).

As of March 4, 2020, the recommendation of the World Health Organization (WHO) is that all medical staff and patients to wear a PROTECTIVE MASK inward the department or hospital. This method of "universal masking" has proven benefits in preventing the contamination of medical staff and patients, respectively the prevention of inhospital or community micro-outbreaks $(18,19)$.

\section{How to use PPE in the endoscopy department}

1. Attach the cap.

2. Perform the hand hygiene (after removing jewelry, watch, etc.).

3. Wear the long sleeved fluid repellent gown (ask a colleague for help to close the back gown).

4. Position the face mask (for respirators FFP2 / FFP3 / N95. It is mandatory to be tested after mounting) in such a way as not to restrict the nonfiltered airflow.

5. Apply the eye-protection: goggles and / or visor.

6. Put the gloves (for high-risk patients use 2 pairs of gloves, the first pair covering the sleeves of the gown, and the second is the working gloves).

\section{Removal of PPE after endoscopy procedures (a phase with major risk of contamination) (20)}

1. Hand hygiene (alcohol-based disinfectant, minimum 30 seconds).

2. Remove the contaminated gloves.

3. Hand hygiene.

4. Remove the waterproof protective gown together with the second pair of gloves.

5 . Hand hygiene.

6. Remove the visor and goggles (do not touch the potentially contaminated components).

7. Hand hygiene.

8. Removing the cap (do not touch the possibly contaminated front part).

9. Leave the probable aerosolized room.

10. Hand hygiene.

11. Remove the respirator (do not touch the potentially contaminated components respiratory part).

12. Hand hygiene. 


\section{Patients "dress code" in the endoscopy department}

1. All patients entering the endoscopy department will wear a protective surgical mask!

2. In addition, those selected as high-risk will wear a surgical mask and gloves received when entering the clinic.

3 . The mask will be removed before starting the endoscopic procedure.

4. The patient will wear a surgical mask again as soon as the sedative effect has over (O2 saturation over $90 \%$ with air).

\section{How to use PPE in the operating room?}

The medical staff from the operating rooms is familiar with the PPE using protocol, hence we will not detail the methodology in these recommendations. Of interest, however, for the entire anaesthetic-surgical team is the use of high-risk PPE required while performing laparoscopic surgery on positive or unconfirmed COVID-19 patients (21). Due to the fact that these situations should not be epidemiologically compro $\neg$ mised, the steps of wearing and removing the specific equipment should be the subject of systematically organized training workshops at the level of each surgery department.

\section{Protective Equipment for Medical Staff}

The configuration of protective equipment used in endoscopy or surgery clinics depends on the degree of exposure of medical staff to infectious risk, and is regulated by the recommendations of the Romanian Ministry of Health (22). In this regard, the medical staff will wear (Table 1):

\section{Protective equipment for digestive endoscopy}

Waterproof protective equipment (Level 1) for semi-urgent / elective endoscopic procedures in patients with NEGATIVE RT-PCR results. Proctological interventions are also included in this category.

- Waterproof surgical gown;

- 2 pairs of gloves (change the outer pair for each patient);

- FFP2 / FFP 3 / N95 respirator;

- Goggles and / or visors;

- Waterproof cap;

- Waterproof shoe protection.

Protective equipment with overall gown (Level 2) - for urgent endoscopic procedures in patients with RT-PCR test in progress or POSITIVE or for a suspected patient requiring oxygen therapy or oro-tracheal intubation.

- A special overall gown;

- 2 pairs of gloves (change both for each patient);

- FFP2 / FFP 3 / N95 respiratory mask;

- Goggles and / or visors;

- Waterproof shoe protection.

\section{Protective equipment for laparoscopic surgery}

Waterproof protective equipment (Level 1) -

Table 1. The type of equipment for endoscopic / laparoscopic procedures depending on the patient's risk of being infected with the SARS-VOC-2 virus

\begin{tabular}{ll}
\hline Low risk patient & High risk patient \\
\hline $\begin{array}{l}\text { - asymptomatic / no contact with COVID-19 or suspected patients / } \\
\text { not traveling from areas with community transmission (<14 days) }\end{array}$ & $\begin{array}{c}- \text { shows symptoms (fever, cough, dyspnoea, diarrhoea) / } \\
\text { contact of COVID-19 or suspected patients / traveling from } \\
\text { areas with community transmission }\end{array}$ \\
\hline - negative RT-PCR test & $\begin{array}{l}\text { positive RT-PCR test or in progress of testing } \\
\text { Level 1 PPE }\end{array}$ \\
\hline FFP2 / FFP3 / N95 respirator & FFP2 / FFP3 / N95 respirator \\
\hline Goggles and / or visors & Goggles and / or visors \\
\hline Long waterproof gown & Overall gown \\
\hline 2 pairs of gloves & 2 pairs of gloves \\
\hline Disposable waterproof cap & Disposable waterproof cap \\
\hline
\end{tabular}


for semi-urgent / elective laparoscopic procedures in patients with NEGATIVE RT-PCR result

- Waterproof long sleeved gown;

- 1-2 pairs of gloves;

- FFP2 / FFP 3 / N95 respiratory mask;

- Eye protection (Goggles);

- Waterproof cap;

- Waterproof shoe protection.

High protection equipment (Level 2) - for urgent laparoscopic procedures in patients with RT-PCR test in progress or POSITIVE or for patients suspected requiring oxygen therapy or intubation.

- A special overall gown or 2 long sleeved fluid repellent gown + cap;

- 2 pairs of gloves;

- FFP2 / FFP 3 / N95 respirator;

- Goggles;

- Fascial Shield;

- Waterproof shoe protection.

The protection of medical staff is fundamental for the medical care safety in the conditions of the COVID-19 pandemic and not only. Hence, members of the endoscopic/ surgical teams should be trained for the correct use of personal protective equipment (PPE). The staff skills' acquisition is mandatory for complying, without compromise, with the rules of correct use of PPE and it requires institutional educational programs such as workshops for the donning and doffing of PPE.

\section{Department / Hospital Adaptations}

The COVID-19 pandemic required the reorganization and reduction of current endoscopic and laparoscopic activities, admitting only the urgent procedures and postponing the semi-urgent and / or elective procedures (including screening for early detection of digestive cancers) (4-8). Prioritization of procedures has become essential for reducing patient flow, to prevent the PPE, beds (especially intensive care) and ventilators' shortage. On the other hand, blocking semi-urgent and elective endoscopic and laparoscopic procedures (especially those for potential cancer patients) increases the number of patients who need to be re-scheduled and prioritized as the epidemiological trend is downward. Moreover, cancer patients require additional measures and procedures based on multidisciplinary decisions, as the impact on morbidity and mortality cannot be neglected $(23,24)$.

In order not to overcrowd the initial triage sector and the waiting rooms, but also the examination rooms, virtual consultations performed remotely, through-out telemedicine systems that allow audio-video interaction and viewing of preloaded medical documents, are preferable (25). Also, internal meetings within departments and even multidisciplinary meetings (tumor board) are recommended to take place virtually for minimizing the number of people in the same room (26).

\section{Triage of medical staff + patients}

The hospital staff should be monitored daily, by checking the body temperature when entering the hospital, but also by systematic RT-PCR testing, depending on the institutions' particularities, symptoms and epidemiological context.

For the scheduled endoscopic investigations or procedures, we recommend a preliminary epidemiological triage of all patients, performed preferably by telephone, 24 hours before the admission in the endoscopy unit. At admission, the epidemiological triage will be performed again, checking for the respiratory symptoms (cough, fever, dyspnoea $=$ shortness of breath, etc.) or digestive symptoms (nausea and vomiting, diarrhoea, loss of appetite, diffuse abdominal pain), together with vital parameters (temperature, pulse, BP, O2 saturation). According to the surveillance methodology of acute respiratory syndrome related to the new coronavirus (COVID-19), updated on 28.04.2020, the suspicious cases and close contacts, in addition to the confirmed cases, are clearly defined. These definitions allow the stratification of patients and their engagement on the correct epidemiological circuit (27).

\section{Patient testing}

Elimination of intra-institutional transmis- 
sion of the SARS-VOC-2 virus plays a key role in controlling the spread of the pandemic. This ensures the safety of medical staff and patients who will undergo minimally invasive endoscopic and / or laparoscopic procedures will be performed, especially immunosuppressed patients (e.g. cancer patients).

We recommend systematic testing, using the RT-PCR method, 24-48 hours before procedures, to all patients who will undergo minimally invasive endoscopic or laparoscopic procedures (28). This will allow to separate SARS-CoV-2 patients into high and low risk, hence protecting healthcare professionals and the rest of the patients who may have other comorbidities (non-COVID-19). Until the confirmation of the RT-PCR result, patients will self-isolate or be isolated in an intermediate sector, intended for potentially asymptomatic infected patients and treated by properly equipped care givers. This protocol will have an impact on the protection of medical staff, limiting the risk of epidemic micro- outbreaks in the hospital. However, a single negative $R$ T-PCR test for SARS-CoV-2 does not rule out the presence of infection, and the serological tests (which allow the detection of IgG and IgM antibodies) do not have a well-defined sensitivity and specificity (29).

On the other hand, given the limitations of the RT-PCR test (relatively low sensitivity), patients with semi-urgent or high-priority elective procedures (e.g. cancer patients) should be investigated extensively, with thoracic computed tomography (CT) assessment (without contrast) being useful (30). Thus, the detection of SARS-COV-2 using RT-PCR has a relative sensitivity similar to $\mathrm{CT}$, none of them being perfect (31). A recent meta-analysis showed that the positive predictive value of CT outside China ranges between $1.5 \%$ and $30.7 \%$, while for RT-PCR it was between $47.3 \%$ and $96.4 \%$, with a high negative predictive value, up to $99.8 \%$ for both techniques (31).

If the patients are tested negative for SARS-COV-2 (and with normal chest CT, if available), they will be referred to nonCOVID-19 departments and a scheduled endoscopic or laparoscopic procedure will be performed. Patients will be closely monitored throughout the hospitalization period and, if necessary, may be retested if clinical / radiological / biochemical suspicions of COVID-19 disease arise. Patients with a positive RT-PCR test (or with suspicious CT appearance), whose endoscopic / laparoscopic procedure may be delayed, will be referred to COVID-19 positive wards. If the procedure is urgently needed, it will be performed in accordance with all personal protective protocols described for high-risk patients.

It would be desirable to contact patients by telephone within 7-14 days after discharge to verify the possible presence of respiratory or digestive symptoms of SARS-COV-2.

\section{Circuits}

Medical institutions (clinics and hospitals) that undertake minimally invasive endoscopic and laparoscopic procedures should consider prioritizing and stratifying the indications according to the phases of the pandemic and the available medical resources, but also the possibility of organizing separate circuits for SARS-CoV-2 positive patients, besides SARS-CoV-2 negative patients. The two circuits should include wards, operating rooms, intensive care units, radiology and endoscopy units, as well as related staff dedicated to infected and uninfected patients, respectively (28). Medical staff teams (especially those providing emergency services, with high-risk COVID-19 patients) are organized in shifts, sequentially for a certain period (e.g. for 5-7 days), followed by RT-PCR testing, in order to prevent infection of all doctors with the same specialty or medical personnel in the same department.

RT-PCR testing in all patients and the systematic evaluation by chest CT of patients scheduled for endoscopic or laparoscopic procedures is recommended 24-48 hours before each procedure. Patients confirmed SARS-CoV-2-positive will be transferred to designated COVID-19 hospitals or to COVID-19 wards of the same hospital, if any. 


\section{Informed consent}

Patients scheduled for endoscopy or laparoscopy should be adequately informed that:

- Due to the variable accuracy of the current tests, regardless of the preventive activities and epidemiological measures established by the medical institution (in accordance with the regulations in effect), it cannot be guaranteed that patients will not come in contact with the SARS-VOC-2 virus.

- Patients at high risk or with SARS-COV2 infection may have increased morbidity and mortality after interventional and laparoscopic endoscopic procedures, especially those performed for semiurgent or urgent indications (28).

\section{ENDOSCOPIC DIAGNOSTIC AND THERAPEUTIC PROCEDURES}

\section{Endoscopy unit adaptations}

Endoscopic procedures imply an increased risk of infection for both patients and healthcare workers (28). The increased risk occurs because the procedures generate aerosols, especially upper digestive endoscopy (including endoscopic ultrasound, endoscopic retrograde cholangio-pancreatography or enteroscopy), but also lower digestive endoscopy (rectosigmoidoscopy or colonoscopy). The digestive tract has a large number of ACE- 2 receptors, in addition viral particles were detected in the digestive tract secretions and faeces, respectively, for a longer period than in samples collected at the nasopharyngeal level $(32,33)$. A recent meta-analysis demonstrated the presence of SARS-CoV-2 RNA in $48.1 \%$ of faecal samples from COVID-19 patients (10).

Aerosol particles produced during endoscopic interventions cannot be controlled, so all team members and all medical staff will wear appropriate protective equipment (including respirator FFP2 / FFP3 / N95, cap, goggles + visor, long waterproof coats and shoe protection (8). Additionally, electrosurgical units should be set to the lowest possible set- tings, and the use of monopolar electrosurgery and bipolar or argon plasma coagulation devices should be kept to a minimum as they may lead to particles aerosolisation.

\section{Timing of Endoscopic Procedures}

According to the recommendations of international associations (4-8), the endoscopic procedures are prioritized as it follows:

\section{Urgent procedures}

- acute upper/lower GI bleeding, including rectal bleeding with hemodynamic instability;

- severe anaemia with cardiovascular complications and hemodynamic instability;

- obstructive jaundice + cholangitis;

- foreign body ingestion;

- dysphagia influencing the oral nutrition.

\section{Semi-urgent procedures}

The decision will be taken multidisciplinary, for each case, and the procedure will be scheduled within a maximum of 1-3 weeks, patients being confirmed with NEGATIVE RT-PCR prior to the procedure:

- assessment of severe symptoms or suspected cancer (alarm symptoms: weight loss, dysphagia, severe anaemia without cardiovascular complications, melena / rectal bleeding without hemodynamic decompensation, obstructive jaundice, acute biliary pancreatitis with suspected common bile duct stones, tumor suspicion on US/CT/MRI scans);

- polypectomies (especially complex ones), for polyps with dysplasia;

- diagnosis (biopsies or fine needle aspiration) for neoplastic conditions;

- cancer staging;

- palliation of gastrointestinal obstruction;

- ulcerative colitis / Crohn's disease (new cases);

- opportunistic screening for gastric / colorectal cancer, respectively patients with a positive FIT test; 
- placement of percutaneous gastrostomy.

NB Screening of patients with medium-risk for colorectal cancer (performed either by annual FIT tests, followed by colonoscopy for positive patients or directly by colonoscopy performed every 10 years) and follow-up of patients with high risk of esogastric/colorectal cancer who require colonoscopic examinations at predefined intervals (Lynch syndrome, etc.) are considered elective procedures that must be prioritized. Resumption of screening programs is an extremely important goal, as late procedures can increase morbidity and mortality (5).

\section{Elective procedures}

Can be postponed for at least 3 months, depending on the epidemiological evolution:

- follow-up of gastric / colon cancer in previously operated patients;

- follow-up of the healing of esophagitis / ulcer / gastritis;

- follow-up of previously resected gastric / colonic polyps;

- patients with functional or minimally symptomatic conditions, with irritable bowel syndrome, GE reflux (bloating, burning, diffuse abdominal pain, etc.);

- procedures for assessing digestive motility.

\section{Pre-procedure assessment}

In the current situation, we recommend RTPCR testing for SARS-CoV-2 24-48 hours before the procedure for all patients who are scheduled for upper or lower diagnostic or interventional endoscopic procedures. Taking into account the methodology for surveillance of acute respiratory syndrome due to the new coronavirus (COVID-19), updated on 28.04. 2020 by INSP (27) asymptomatic cancer patients may be prioritized for RT-PCR testing before surgery or invasive maneuvers. Furthermore, it is clearly specified that medical units may establish test protocols for medical staff and / or patients by RT-PCR, in addition to the INSP prioritization recommendations, tests that can be performed with their own resources in the laboratories they possess or in other laboratories.

For cancer patients, we also recommend performing additionally a chest CT (without contrast agent), used extensively for diagnosis in medical systems where RT-PCR tests are insufficient due to the large number of patients, 24-48 hours before performing endoscopic diagnostic procedures and staging.

Taking into account the epidemiological context and the dynamic evolution at regional and local level of the SARS-CoV-2 pandemic, biological tests can be recommended, according to the indication of the attending physician, including: complete blood count with platelets, ESR 1h / 2h, fibrinogen, C-reactive protein, glycaemia, urea, creatinine, lactate dehydrogenase, creatine phosphokinase, blood iron, ferritin, total bilirubin, direct bilirubin, indirect bilirubin, AST / ALT, AP / GGT, coagulation tests (PT, INR, APTT), procalcitonin, D-dimers, amylase, lipase, etc. Patients on anticoagulant therapy will be evaluated according to international guidelines (ESGE / ASGE) and local institutional protocols (34).

\section{Recommendations for endoscopic procedures (Fig. 1)}

All emergency endoscopies will be considered as having an increased risk of contamination, because COVID-19 positive patients may present with gastrointestinal clinical symptoms. Endoscopic equipment used for COVID19 positive or suspicious patients should be cleaned separately from other endoscopic equipment (8), while accessories and consumables should be disposable. For positive or suspected COVID-19 patients, evaluation by separate epidemiological circuits is required, in an endoscopy room with operating room circuits, if possible with negative pressure (12). PPE is of a high standard, with disposable overall gowns, FFP2 / FFP3 / N95 respirators, visors, goggles, 2 pairs of gloves, waterproof leg protection, etc. If possible, the endoscopy tower and related endoscopes (gastroscope, colonoscope, duodenoscope, echoendoscope, etc.) will remain the same during the COVID-19 pandemic. 
Figure 1. Algorithm for Endoscopic Procedures During the COVID-19 Pandemic

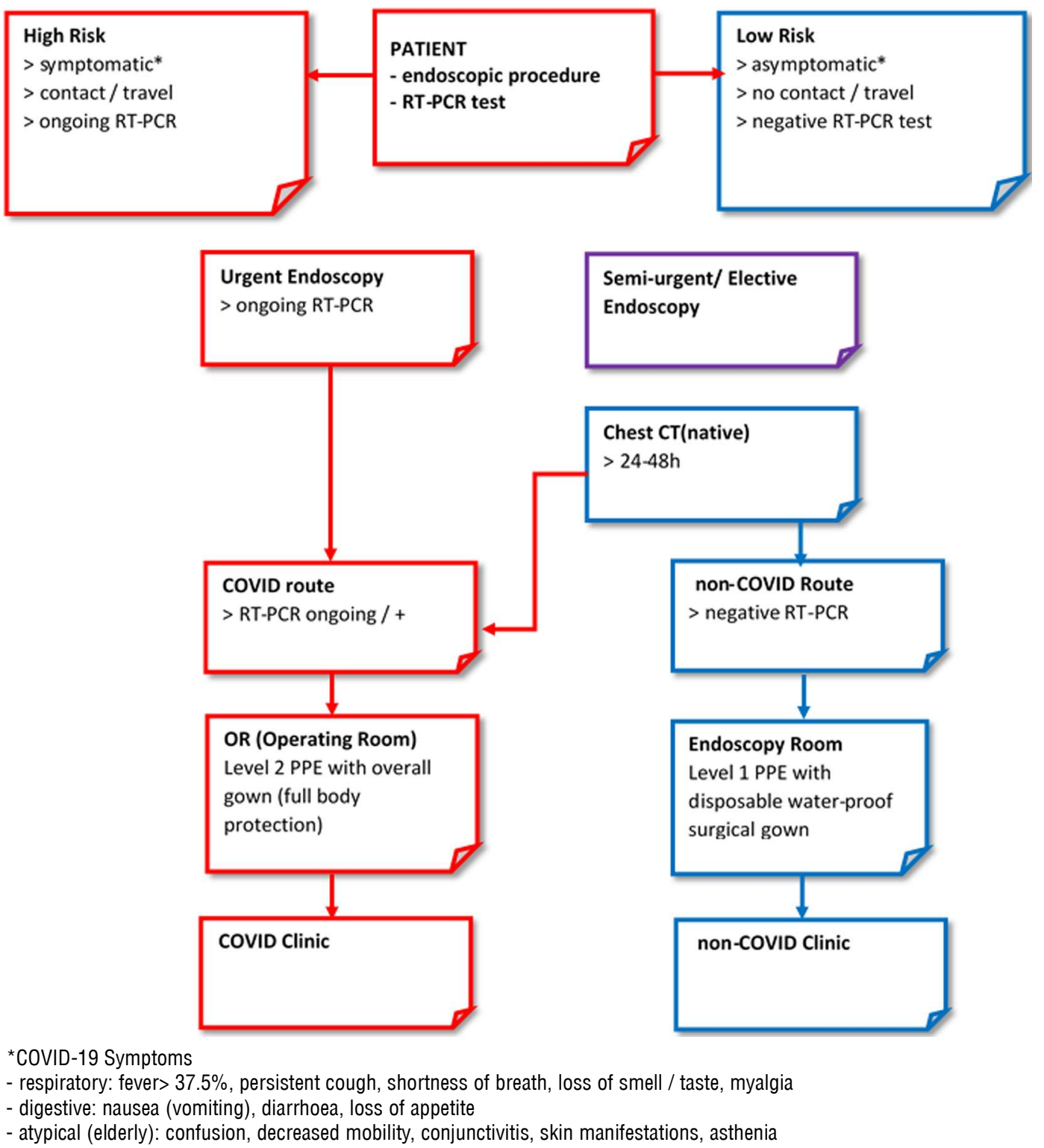

For patients with semi-urgent procedures (preferably scheduled within a maximum of two weeks) and elective procedures, risk minimization measures are required, including RT-PCR testing, eventually chest CT 24-48 hours before the procedure, especially for cancer patients who may be immunosuppressed and therefore have an increased risk of COVID-19. Endoscopic procedures in low-risk patients (negative RT-PCR) may be performed in the non-COVID endoscopy unit, with minimal medical staff, preferably with propofol sedation, under the supervision of the anesthetist (deep sedation increases the quality of procedures, minimizes the effort of vomiting and coughing of patients which may exacerbate the aerosolization phenomenon). It is preferable to couple the procedures during the same sedation; the oxygen therapy should be administered on the mask.

Even after a negative RT-PCR test and a normal CT scan, ALL patients are considered 
at risk, requiring the use of waterproof protective equipment for the gastroenterologist, anesthetist, endoscopy nurse and anesthetist nurse throughout the procedure.

\section{Post-procedure Measures}

After the procedure, the individual waterproof protective equipment is disposed in dedicated containers! The medical staff who participated in the procedure and the type of PPE used for that case are recorded in the care plan. The institutional protocols for the management of contaminated waste and the cleaning and disinfection procedures will be followed, with keeping a sufficient time interval between the procedures.

Decontamination of the endoscopy laboratory for the micro-aeroflora of the endoscopy room is made with a UV lamp (after sealing the septic tanks). Following the first sterilization of the air, time should be allowed for the cleaning staff who will enter equipped and will take care of the disinfection of the room by wiping all surfaces and washing the floors with chlorine detergent solutions, respectively aeration, as much as possible with fresh air.

\section{Equipment decontamination}

The high-level disinfection procedures of the endoscope should be respected according to the ESGE / ESGENA guidelines, preferably using automatic systems (8). The endoscopes are reprocessed following the standard steps, eliminating, if possible, the risk of splashing, preferably manual reprocessing, followed by automatic disinfection in the washing machine. Reprocessing will be carried out with closed doors but with wide opened windows, by the properly equipped nurse, the access of another person being forbidden. Accessories are mandatory to be single use (valve channel, mouthpieces, washing pump connectors, intervention accessories, cleaning brushes, etc.).

\section{Resuming Endoscopic Procedures}

Up until now, the elective endoscopic procedures (and in many cases those semi-urgent too) have been postponed; however, the current status of the COVID-19 pandemic (the flattening of the curve) gives the opportunity to slowly resume the endoscopic procedures, including the elective endoscopies. In order to safely perform endoscopic activity, the following safety measures should be taken into consideration:

1. Endoscopic procedures will be prioritized by risk (urgent, semi-urgent, including oncology patients, elective)

A special aspect is the screening of patients at medium risk of colorectal cancer (performed either by annual FIT tests, followed by colonoscopy for positive patients or directly by colonoscopy performed every 10 years) which is currently postponed indefinitely in healthcare systems. Similarly, the patients who are at high risk for colorectal cancer and require colonoscopy at predefined intervals (Lynch syndrome, etc.) are also currently delayed. These categories of patients should be prioritized for elective endoscopic procedures as soon as the acute phase of the COVID-19 pandemic is overcome. The resumption of screening programs is an extremely important objective, as late performance of procedures can increase morbidity and mortality (35). We strongly recommend SARS-CoV-2 RT-PCR testing before performing screening endoscopic procedures.

2 . The epidemiological triage of all patients will be performed initially by phone (epidemiological questionnaire), and before entering the endoscopy unit. In addition, the daily epidemiological triage of medical staff (including thermometry) is also required.

3. All patients scheduled for endoscopic procedures will be tested (RT-PCR) for active SARS-CoV-2 infection, 24-48 hours before the procedure. They will be instructed to remain in self-isolation during this period, until the test results are ready. Cancer patients may undergo chest CT (native) depending on the indications of staging or individual decisions of the attending physician. Patients with suspected COVID-19 are isolated and referred to dedicated COVID hospitals.

4. Endoscopy Department staff will be systematically (or in case of symptoms) tested 
(RT-PCR) for active SARS-CoV-2 infection.

5. Policies on social distancing for patients will be implemented:

- Mandatory use of surgical masks by both medical staff and patients.

- Appropriate distancing of beds in the recovery area

- Appropriate distancing of patients in the waiting area.

- Distancing endoscopic procedures with increased time intervals.

- Restricting the access of visitors including the family members.

6. Wearing protective equipment by all team members involved in the endoscopic procedure is mandatory. They will wear the appropriate protective equipment, including gloves, FFP2 / 3 mask, goggles + face shield, boots, hairnet, and gowns (8). In addition, electrosurgical units should be set to the lowest possible values, and the use of monopolar electrosurgery and bipolar or argon plasma coagulation devices should be kept to a minimum, as they may lead to aerosolization of viral particles.

7. Careful disinfection of endoscopes will be performed following the internal guidelines already implemented. Only disposable accessories will be used.

8. Oro-tracheal intubation for patients with elective procedures is not recommended. Oxygen therapy is preferable because aerosolization is minimized (6).

\section{LAPAROSCOPIC, DIAGNOSTIC AND THERAPEUTIC PROCEDURES}

Diagnostic and/ or therapeutic laparoscopic surgery will be performed based on the degree of competence of the operating team, institutional protocols, as well as the availability of specific equipment.

\section{Prioritization of Laparoscopic Procedures}

According to the national and international guidelines and national regulations (36), in the context of COVID-19 pandemic, laparos- copic interventions should be prioritized based on a multidisciplinary consensus, as follows:

\section{Immediate emergencies}

- upper digestive haemorrhage (hematemesis) with hemodynamic impact;

- lower digestive haemorrhage with hemodynamic impact;

- genital haemorrhages with hemodynamic impact;

- visceral ischemia (renal, entero-mesenteric, hepatic, splenic);

- abscess or phlegmon with septic status;

- ischemic colitis;

- peritonitis;

- ectopic pregnancy.

\section{Emergencies that can be delayed up to 24}

hours

- upper digestive hemorrhage

(hematemesis);

- lower digestive hemorrhage;

- genital bleeding;

- evacuated hydatid cyst;

- acute cholecystitis or acute cholangitis;

- total oropharyngeal or esophageal dysphagia;

- intestinal occlusions (including inguinal hernias, internal hernias with occlusion);

- obstructive jaundice;

- malignant lymphomas with compressive lymph nodes;

- penetration and perforation of ulcers;

- acute pancreatitis;

- acute peritonitis;

- acute inflammatory pathology of the uterus and appendages;

- haemorrhagic proctocolitis - acute onset toxic megacolon;

- septic syndromes;

- acute and chronic exacerbated suppurations;

- dysfunctional uterine bleeding;

- bleeding malignancies;

- abdominal injuries;

- neuroendocrine tumors with carcinoid syndrome. 
Aggravating pathologies that must and can

be scheduled in a maximum of 1-3 weeks

- malignant or potentially malignant pathology

- incarcerated inguinal hernia;

- intermittent internal hernias;

- severe reflux pathology.

\section{Pathologies that can be scheduled electively}

- bariatric / metabolic surgery;

- uncomplicated abdominal hernias;

- uncomplicated gallstones;

- gastroesophageal reflux disease, etc.

\section{Pre-procedure Assessment}

Preoperative evaluations and triage are similar to those described above for interventional endoscopies. These are consisting of: RT-PCR test, chest CT and blood work. All emergency surgeries requiring the prompt application of specific surgical or endoscopic treatment prior to confirmation of infection with the new coronavirus (SARS-CoV-2) requires that all patients will be considered at high risk for COVID-19. Consequently, surgical or endos-copic interventions will be performed using specific PPE for SARS-CoV-2positive patients.

Figure 2. Algorithm for Surgical Interventions During the COVID-19 Pandemic

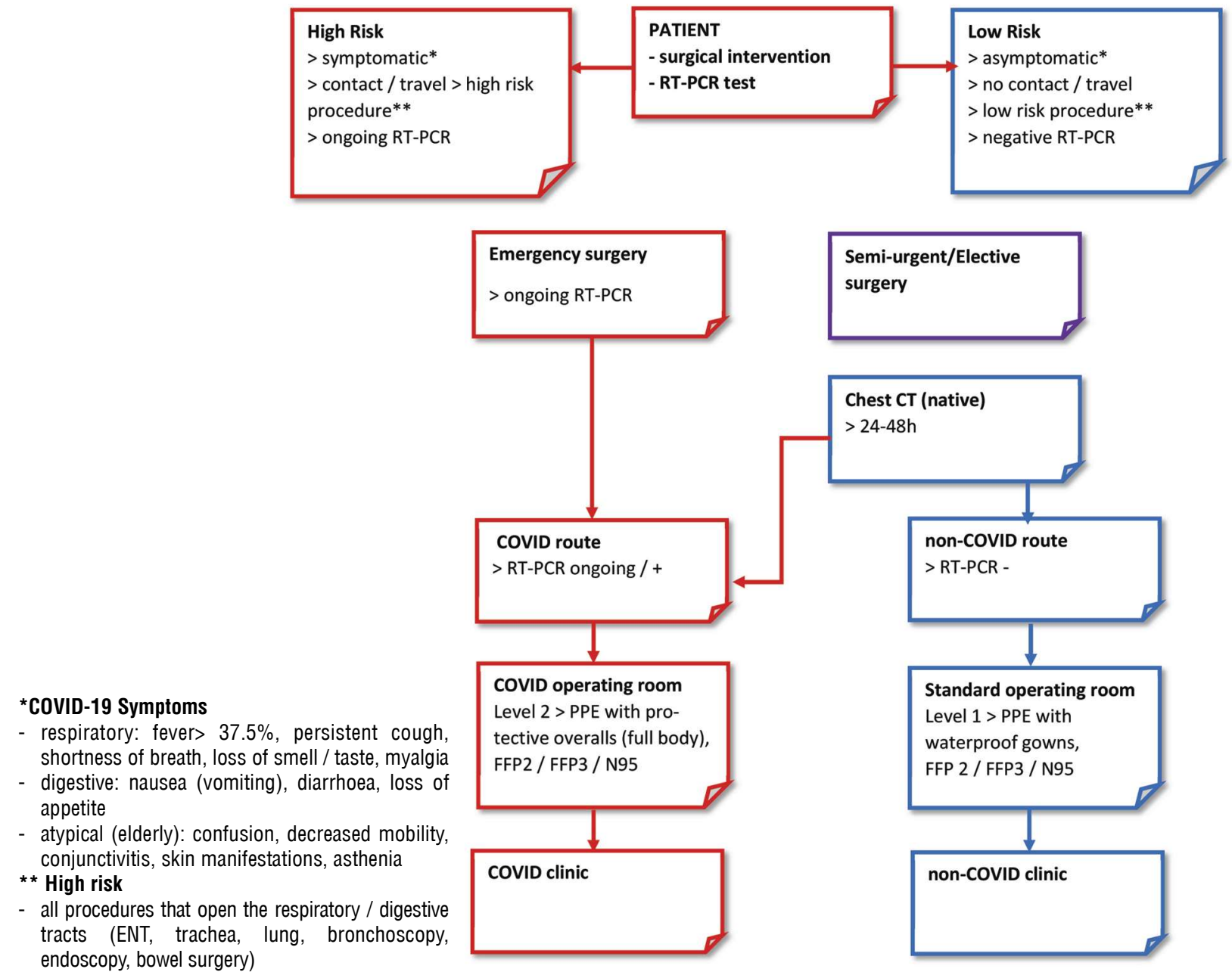




\section{Recommendations for the Activity in the Operating Rooms (Figure 2)}

In case of a surgical (classic or laparoscopic) intervention for a patient confirmed or suspected of infection with SARS CoV-2, the operating team will consider both the safety of the surgical act and the control of the infectious risk, and will abide the following recommendations:

- Dedicated operating rooms must be equipped with appropriate filters and proper ventilation systems. If possible, operating rooms with negative pressure will be preferred for interventions performed on COVID-19 positive patients.

- Members of the surgical team will be equipped with appropriate protective equipment (PPE), filter masks FFP2 / FFP3 / N95 filters, waterproof caps, face shields, coveralls (if not available can be replaced with waterproof gowns), double gloves, waterproof leg protections, according to the regulations of the Ministry of Health (33). On the other hand, the excessive use of PPE should be avoided by following the recommendations of the Ministry of Health and WHO for the rational use of PPE in the context of Covid-19.

- The use of highly protective masks (FFP2 / FFP3 / N95) is recommended for surgical interventions performed on patients confirmed or suspected of COVID-19. Previously, the mask should be checked to fit perfectly on the user's face, making sure that there is no space between it and the skin of the face.

- Surgical (laparoscopic) interventions are performed under general anesthesia and this involves oro-tracheal intubation, extubation and mechanical ventilation, and all these are aerosol-producing procedures. To limit the risk of infection, the surgical team should reduce exposure during intubation and extubation.

- During surgery, the number of people present in the operating room must be kept to a minimum and all the names will be registered in the surgical report.

- The surgical team members moving out from the operating room will be restricted. It is useful to coordinate with outside staff who can deliver the necessary equipment located in other areas of the operating room, if the situation requires it

- The use of laparoscopic surgery is highly dependent on the surgical team expertise, the institutional protocols and procedures as well as the availability of specific equipment and instruments.

- If laparoscopic procedures involve an extended surgical time, in the context of prolonged wearing of high protection equipment with unfavorable ergonomic impact, breaks or conversion to open technique will be considered.

For patients without COVID-19, the use of two waterproof gowns or overalls and gown at the same time, face shields and goggles at the same time only make it difficult to perform the surgery and produce additional consumption of materials. The use of FFP2 / FFP3 / N95 masks, gloves, goggles, waterproof gowns, possibly with the addition of waterproof aprons under these gowns (for procedures with risk of prolonged contact with patient fluids) provides sufficient protection for the operating in case of a negative RT-PCR (and a normal chest CT).

\section{Laparoscopic Surgery During COVID-10 Pandemic}

Data on the possible aerosolization of SARSCoV-2 viral particles during laparoscopic or robotic operations is very limited, and the current recommendations are strongly influenced by this limitation (28).

Looking from a similar perspective, in case of laparoscopic surgery performed in patients with HIV, hepatitis B and C, we noticed that DNA or viral RNA was identified in the smoke produced using electrosurgery in these interventions. On the other hand, there are no articles in the literature documenting an increased risk of viral contamination, related to surgical smoke or pneumoperitoneum loss, for surgeons, anesthetists, or operating room 
staff (37). For patients carrying such viruses for whom surgical treatment is indicated, it is recommended to minimize the exposure of surgeons to contaminated blood and surgical smoke that can be filtered more easily, suggesting the use of laparoscopic techniques, safer from this point of view compared to classic laparotomy (38).

In addition, there is evidence from outbreaks of similar respiratory viruses, such as influenza and other coronaviruses - SARS (severe acute respiratory syndrome) or MERS (Middle East respiratory syndrome), that have shown no evidence of transmission of the disease through surgical smoke or gas losses during laparoscopic surgery (39). On the other hand, the application of all known and available safety measures to reduce the possibility of intraoperative contamination with SARS-CoV-2 virus should be constantly considered. The surgical team must be equipped with appropriate protective equipment (PPE), including FFP2 / FFP3 / N95 masks, face shields, gowns, waterproof caps, coveralls, double gloves, boots, according to the regulations of the Ministry of Health (40).

In the current context of not knowing the potential risk of intraoperative contamination with SARS-CoV-2, patients with surgical pathology can benefit from the advantages of laparoscopic or robotic surgery. In the absence of specific equipment or if there is a limited experience of the operating team in laparoscopic surgery, the minimally invasive approach in a positive COVID-19 patient is not recommended. The SAGES \& EAES recommendations also adopted by ARCE (36) for the use of minimally invasive surgery during the COVID-19 pandemic, emphasize the importance of:

a. lowering the carbon dioxide intrabdominal pressure,

b. smaller incisions for the trocars to prevent the gas leak at the access ports' site;

c. permanent use of an ultrafiltration device (filtered surgical smoke evacuation system) (41)

d. application of measures to limit viral contamination when changing instruments during surgery or exsuflation of pneumo- peritoneum, trocars' extraction, conversion to open technique or extraction of the surgical specimen

e. the use of an endo-bag for the specimen and of a wound protector for the its extraction in all patients in whom minimally invasive excisional surgery is performed.

The transanal surgery (TAMIS / TaTME), due to its specificity of the work platforms, may associate an increased risk of aerosolization; moreover, SARS-CoV-2 viral particles have been detected in the stool (33). In patients with negative RT-PCR (and normal chest CT), transanal surgery may be used to remove rectal tumors that cannot be removed endoscopically only if the surgical team takes appropriate precautions that include the FFP2 / FFP3 / N95 mask, goggles / face shield, surgical gown, 2 pairs of gloves, boots, etc.

In the current context of the pandemic, all the transanal interventions, for example TAMIS / TaTME that have an equivalent in the minimally invasive approach without transanal access, and in those cases where the surgical smoke cannot be ultrafiltrated or in the absence of specific personal protective materials, this approach is not recommended (28).

\section{Post-procedural Considerations}

Complies with the same principles mentioned above for endoscopic procedures with regard to the storage of used protective equipment in dedicated containers, the registering of medical staff involved in the patient care and the type of PPE used, in line with institutional protocols for contaminated waste management, keeping a sufficient time between procedures are all mandatory.

Also, if in the postoperative follow-up, the care givers notice clinical changes or laboratory / imaging signs suggestive of COVID-19, they will consider retesting the recently operated patients by RT-PCR.

\section{Resumption of Surgical Activity}

Before restarting elective laparoscopic surgery, 
it should be taken into account the local capacity of the institution (sufficient staff, number of beds, testing capacity, operating rooms, intensive care units, sufficient protective equipment, etc.), the potential organizational and economic consequences of the pandemic, but also the possibility of subsequent waves of COVID-19. If phase 3 of the epidemic is demonstrated, confirmed by a decrease in the number of diseases at institutional or regional level, the premises for resuming elective activity are met.

At the institutional level, the implementation of triage and testing protocols for inpatients as well as, planned testing the medical staff are recommended before deciding to resume endoscopic and laparoscopic activity.

Exercises and ongoing training of all staff in compliance with safety protocol and patient circuits should be continued because we should not expect to return to a "normal" pre-pandemic healthcare environment soon, and the above rigorous recommendations are likely to be required for a longer period of time. This training should be also to the environmental and non-medical staff.

The OR workflow should be reconsidered according to institutionally established safety protocols and safety circuits.

Surgical procedures will continue to be prioritized in the future based on the dynamic evolution of pandemics.

Establishing a coherent prioritization program based on the principle of transparency will provide safety, consistency and reliability and it will help with the integration of decisionmaking factors that are not normally considered in clinical judgment outside this particular pandemic / post-pandemic situation.

Both during the pandemic and later, until the recovery of the previous balance, we recommend an active communication with patients, supported by all available means. Thus, patients will explicitly realize that they have not been abandoned. Clear messages should be used to inform about safety within the healthcare system, testing policy, safety circuits, transparency in prioritization, wearing protective equipment, visits of relatives, the postoperative period, follow-up and retesting procedures.

\section{Education and Training Activities}

The educational activities should continue. This critical situation that Romanian healthcare system has gone through is a clear proof of the need for training and the need for inter-unit coordination in which meritocracy is the guiding principle. In addition, the educational training for gastroenterology and surgery residents has been profoundly influenced during this pandemic.

During this period, the priority of the medical system is to provide the population with the best possible care, while protecting the medical workforce. However, despite the continuing pressure on our health care system, medical education must not be abandoned. Maintaining continuity in medical training while protecting our students must be done while ensuring the sustainability of a critical workforce for our healthcare system. At the same time, a reduction in the capacity of trainees and educators to participate in educational opportunities due to competing professional and personal priorities, such as continuous clinical service on the "front line", disease risk, family responsibilities, (schools, kindergartens are closed) or financial considerations (42).

The health and safety of our trainees must be the basic idea of all training programs during this period (43). Unnecessary risks of transmitting the SARS-CoV-2 virus, associated with educational activities, must be eliminated. Distance learning activities using interactive online technology opportunities must be the new routine and can be developed through the use of digital e-learning platforms. Conferences and courses must be held in a virtual environment through dedicated platforms, while the practical activity (hands-on) will be interrupted for now. Residency programs must invest in virtual platforms available to all trainees. Practical training of technical skills is difficult in the virtual environment, but there are innovative approaches using simulators and 
evaluation of results with video feedback. Basic knowledge testing, clinical case analysis, diagnostic and therapeutic evaluations are examples of formats that can be used in the virtual environment. Current platforms allow online follow-up of sur-geries or endoscopic procedures that can be structured in welldefined stages and explained step by step to trainees.

\section{Conclusions}

Although medical societies have an important advisory role in different countries, there is still a lack of evidence-based guidelines or clinical algorithms related to local or national epidemiological evolution of COVID-19. Recommendations based on surveys and / or expert opinions are not strong enough to persuade and be followed by key stakeholders, including medical staff and hospital administrators, with negative consequences for patients who are deprived of immediate minimally invasive interventions and high quality during this pandemic. Furthermore, the regional severity gradient of the COVID-19 pandemic in Europe, between North-South and East-West, should be taken into account in the universal guidelines and recommendations, which it certainly cannot be considered a priority over regulations and government methodologies.

The objectives of the SRED and ARCE recommendations target the endoscopic and laparoscopic surgery activities, to support their non-discriminatory used for diagnostic or therapeutic purposes, pursuing the demonstrated benefits of these procedures, in safe conditions for patients and medical staff. This guideline has indicative value for the development of local protocols. Moreover, these recommendations may require modifications, depending on the evolutionary path of the current pandemic and the national regulations.

Work group

Adrian Săftoiu, Cătălin Copăescu, Marcel Tanțău, Victor Tomulescu, Cristian Gheorghe

\section{Board members SRED}

Marcel Tanțău, Adrian Săftoiu, Cristian
Gheorghe, Eugen Dumitru, Bogdan Mateescu, Lucian Negreanu, Mariana Jinga, Andrada Seicean, Mihai Ciocîrlan, Vasile Drug, Mircea Mănuc.

\section{Board members ARCE}

Cătălin Copăescu, Ciprian Duță, Victor Tomulescu, Răzvan Popescu, Călin Tiu, Vasile Bințințan, Valentin Calu, Valeriu Şurlin, Florin Turcu, Florin Zaharie, Dan Ulmeanu, Dan Brebu, Nicolau Alexandru, Mircea Lițescu, Bogdan Diaconescu.

\section{Useful Links}

1. PPE (Center of Disease Control USA): https://www.youtube.com/ watch?v=t11xq20Uy-U

2. Donning PPE (National Health System UK): https://www.youtube. com/watch?v=kKz_vNGsNhc

3. Doffing PPE (National Health System UK): https://www.youtube. com/watch?v=0U0501JmLH0

4. CNSCBT: http://www.cnscbt.ro/index.php/informatii-pentru-personalul-medico-sanitar/1636-ghid-privind-echiparea-cu-echipament-de-protectie-individuala/file

5. CNSCBT: http://www.cnscbt.ro/index.php/informatii-pentru-personalul-medico-sanitar/1600-echipare-si-dezechipare-echipamente-protectie/file

6. Disinfection: https://www.youtube.com/watch?v=j5_5RgGniDc\&t=261s

7. Recommendations ESGE/ESGENA: https://www.esge.com/esgeand-esgena-position-statement-on-gastrointestinal-endoscopyand-the-covid-19-pandemic/

8. Recommendations ASGE/AGA/ACG: https://www.asge.org/home/ joint-gi-society-message-covid-19

9. Recommendations BSG: https://www.bsg.org.uk/covid-19-advice/ endoscopy-activity-and-covid-19-bsg-and-jag-guidance/

10. Recommendations ACG: https://gi.org/media/covid-19-and-gi/

\section{Acknowldegements}

We are grateful to Dr. Alina Constantin and Ms. Daniela Elena Burtea for their critical support in drafting certain parts of the manuscript. Also, translation into English has been kindly provided by Dr. Irina M. Cazacu and Dr. Irina Cherciu. We thank the Group of Young Gastroenterologists in Romania for their feedback on educational needs during COVID-19 pandemic.

\section{Conflict of Interest}

The authors declare that they have no conflict of interest.

\section{Author's Contributions}

The members of the working group, Adrian Săftoiu, Cătălin Copăescu, Marcel Tanțău, Victor Tomulescu and Cristian Gheorghe equaly 
contributed to the literature research and writting the manuscript. The rest of the authorsverified and approved the SRED-ARCE Recommendations

\section{References}

1. Mavragani A. Tracking COVID-19 in Europe: Infodemiology Approach. JMIR Public Health Surveill. 2020:6(2):e18941.

2. Hartley DM, Perencevich EN. Public Health Interventions for COVID-19: Emerging Evidence and Implications for an Evolving Public Health Crisis. Jama. 2020.

3. FACS A. Joint Statement: Roadmap for Resuming Elective Surgery after COVID-19 Pandemic 2020 (updated Online April 17, 2020. Available from: https://www.facs.org/covid-19/clinical-guidance/ roadmap-elective-surgery.

4. ACG. COVID-19 and GI 2020 (Available from: https://gi.org/media/ covid-19-and-gi/.

5. ASGE. JOINT GI SOCIETY MESSAGE: COVID-19 Clinical Insights for Our Community of Gastroenterologists and Gastroenterology Care Providers 2020 (Available from: https://www.asge.org/ home/joint-gi-society-message-covid-19.

6. BSG. Endoscopy activity and COVID-19: BSG and JAG guidance 2020 (Available from: https://www.bsg.org.uk/covid-19-advice/ endoscopy-activity-and-covid-19-bsg-and-jag-guidance/.

7. Francis N, Dort J, Cho E, Feldman L, Keller D, Lim R, et al. SAGES and EAES recommendations for minimally invasive surgery during COVID-19 pandemic. Surg Endosc. 2020.

8. Gralnek IM, Hassan C, Beilenhoff U, Antonelli G, Ebigbo A, Pellise $M$, et al. ESGE and ESGENA Position Statement on gastrointestina endoscopy and the COVID-19 pandemic. Endoscopy. 2020.

9. Rudan I. A cascade of causes that led to the COVID-19 tragedy in Italy and in other European Union countries. J Glob Health 2020;10(1):010335-

10. Cheung KS, Hung IF, Chan PP, Lung KC, Tso E, Liu R, et al. Gastrointestinal Manifestations of SARS-CoV-2 Infection and Virus Load in Fecal Samples from the Hong Kong Cohort and Systematic Review and Meta-analysis. Gastroenterology. 2020.

11. Pan L, Mu M, Yang P, Sun Y, Wang R, Yan J, et al. Clinical Characteristics of COVID-19 Patients With Digestive Symptoms in Hubei, China: A Descriptive, Cross-Sectional, Multicenter Study. The American journal of gastroenterology. 2020.

12. Sultan S, Lim JK, Altayar O, Davitkov P, Feuerstein JD, Siddique $\mathrm{SM}$, et al. AGA Institute Rapid Recommendations for Gastrointestinal Procedures During the COVID-19 Pandemic. Gastroenterology. 2020.

13. Gu J, Han B, Wang J. COVID-19: Gastrointestinal Manifestations and Potential Fecal-Oral Transmission. Gastroenterology. 2020.

14. Han C, Duan C, Zhang S, Spiegel B, Shi H, Wang W, et al. Digestive Symptoms in COVID-19 Patients With Mild Disease Severity: Clinical Presentation, Stool Viral RNA Testing, and Outcomes. The American journal of gastroenterology. 2020.

15. Coccolini F, Perrone G, Chiarugi M, Di Marzo F, Ansaloni L, Scandroglio I, et al. Surgery in COVID-19 patients: operational directives. World J Emerg Surg. 2020;15(1):25.

16. Repici A, Maselli R, Colombo M, Gabbiadini R, Spadaccini M, Anderloni $A$, et al. Coronavirus (COVID-19) outbreak: what the department of endoscopy should know. Gastrointest Endosc. 2020.

17. Repici A, Aragona G, Cengia G, Cantu P, Spadaccini M, Maselli R, et al. Low risk of covid-19 transmission in Gl endoscopy. Gut. 2020.

18. Advani S, Smith B, Lewis S, Anderson DJ, Sexton DJ. Universal Masking in Hospitals in the COVID-19 era: Is it Time to consider Shielding? Infect Control Hosp Epidemiol. 2020:1-9.

19. Klompas M, Morris CA, Sinclair J, Pearson M, Shenoy ES Universal Masking in Hospitals in the Covid-19 Era. New England Journal of Medicine. 2020

20. Guidance for wearing and removing personal protective equipment in healthcare settings for the care of patients with suspected or confirmed COVID-19 2020 (Available from: https://www.ecdc. europa.eu/sites/default/files/documents/COVID-19-guidancewearing-and-removing-personal-protective-equipment-healthcaresettings-updated.pdf.
21. Placement of Personal Protective Equipment 2020 (Available from: https://www.facebook.com/EAES.eu/videos/209171186975270/?t=7.

22. MS. Ordinul Minitrului Sanatatii $\mathrm{nr}$. 555/2020 privind aprobarea Planului de masuri pentru pregatirea spitalelor în contextul epidemiei de coronavirus COVID-19, a Listei spitalelor care asigura asistenta medicala pacientilor testati pozitiv cu virusul SARS-CoV-2 în faza I si în faza a II-a si a Listei cu spitalele de suport pentru pacientii testati pozitiv sau suspecti cu virusul SARSCoV-2. 7 aprilie 2020 ed. Monitorul Oficial al Romania nr 290/2020

23. Rosenbaum L. The Untold Toll - The Pandemic's Effects on Patients without Covid-19. New England Journal of Medicine. 2020.

24. Schrag D, Hershman DL, Basch E. Oncology Practice During the COVID-19 Pandemic. Jama. 2020.

25. Song X, Liu X, Wang C. The role of telemedicine during the COVID19 epidemic in China-experience from Shandong province. Crit Care. 2020;24(1):178.

26. Dharmarajan H, Anderson JL, Kim S, Sridharan S, Duvvuri U, Ferris $\mathrm{RL}$, et al. Transition to a virtual multidisciplinary tumor board during the COVID-19 pandemic: University of Pittsburgh experience. Head Neck. 2020

27. Definitiile de caz pentru Sindromul respirator acut cu noul coronavirus (COVID-19) 2020 (Available from: https://www.cnscbt.ro/ index.php/1697-definitii-de-caz-si-algoritm-de-testare-pentrucovid-19-actualizare-28-04-2020-1/file.

28. Tomulescu V SV, Scripcariu V, Bintintan V, Duta C, Calu V, Popescu I, Saftoiu A, Copaescu C. Colorectal Surgery in Romania during the COVID-19 Pandemic Recommendations of the Romanian Society of Coloproctology (SRCP) and the Romanian Association for Endoscopic Surgery (ARCE). Chirurgia (Bucur). 2020;115(2).

29. Cevik M, Bamford C, Ho A. COVID-19 pandemic - A focused review for clinicians. Clin Microbiol Infect. 2020.

30. Ai T, Yang Z, Hou H, Zhan C, Chen C, Lv W, et al. Correlation of Chest CT and RT-PCR Testing in Coronavirus Disease 2019 (COVID-19) in China: A Report of 1014 Cases. Radiology. 2020:200642.

31. Kim $\mathrm{H}$, Hong $\mathrm{H}$, Yoon SH. Diagnostic Performance of $\mathrm{CT}$ and Reverse Transcriptase-Polymerase Chain Reaction for Coronavirus Disease 2019: A Meta-Analysis. Radiology. 2020:201343.

32. Huang C, Wang $Y$, Li X, Ren L, Zhao J, Hu Y, et al. Clinical features of patients infected with 2019 novel coronavirus in Wuhan, China. Lancet. 2020;395(10223):497-506.

33. Zhang J, Wang S, Xue Y. Fecal specimen diagnosis 2019 novel coronavirus-infected pneumonia. Journal of medical virology. 2020.

34. Veitch AM, Vanbiervliet G, Gershlick AH, Boustiere C, Baglin TP, Smith LA, et al. Endoscopy in patients on antiplatelet or anticoagulant therapy, including direct oral anticoagulants: British Society of Gastroenterology (BSG) and European Society of Gastrointestinal Endoscopy (ESGE) guidelines. Endoscopy. 2016;48(4):c1.

35. Corley DA, Jensen CD, Quinn VP, Doubeni CA, Zauber AG, Lee JK, et al. Association Between Time to Colonoscopy After a Positive Fecal Test Result and Risk of Colorectal Cancer and Cancer Stage at Diagnosis. Jama. 2017;317(16):1631-41.

36. ARCE. RECOMANDARILE SAGES SI EAES PRIVIND RASPUNSUL CHIRURGICAL LA CRIZA COVID-19 2020 (Available from: https://www.arce.ro/wp-content/uploads/2020/04/RecomandariEAES-SAGES-pentru-perioada-COVID19 ARCE-2020.pdf.

37. Kwak HD, Kim SH, Seo YS, Song KJ. Detecting hepatitis B virus in surgical smoke emitted during laparoscopic surgery. Occupational and environmental medicine. 2016;73(12):857-63.

38. Fry DE. Reduction of HIV transmission during laparoscopic procedures. Surgical laparoscopy \& endoscopy. 1993;3(1):1.

39. Chang L, Yan Y, Wang L. Coronavirus Disease 2019: Coronaviruses and Blood Safety. Transfusion medicine reviews. 2020

40. MS. Masuri recomandate în vederea reducerii impactului pandemiei COVID-19. 2020

41. ARCE. Este chirurgia laparoscopica sigura in timpul pandemiei Covid-19 2020 (Available from: https://www.arce.ro/wp-content/ uploads/2020/04/Este-chirurgia-laparoscopica-sigura-in-timpulpandemiei-Covid-19.pdf.

42. Daodu O, Panda N, Lopushinsky S, Varghese TK, Jr., Brindle M. COVID-19 - Considerations and Implications for Surgical Learners. Annals of surgery. 2020.

43. Shah R, Satyavada S, Ismail M, Kurin M, Smith ZL, Cooper GS, et al. COVID-19 pandemic through the lens of a gastroenterology fellow: looking for the silver lining. Gastrointest Endosc. 2020. 